\title{
TITLE:
}

\section{Involvement of auxin distribution in root nodule development of Lotus japonicus.}

\author{
AUTHOR(S): \\ Takanashi, Kojiro; Sugiyama, Akifumi; Yazaki, \\ Kazufumi
}

\section{CITATION:}

Takanashi, Kojiro ... [et al]. Involvement of auxin distribution in root nodule development of Lotus japonicus.. Planta 2011, 234(1): 73-81

\section{ISSUE DATE:}

2011-07

URL:

http://hdl.handle.net/2433/143584

\section{RIGHT:}

The final publication is available at www.springerlink.com; この論文は 出版社版でありません。引用の際には出版社版をご確認ご利用くださ $\omega_{\circ}$; This is not the published version. Please cite only the published version. 
Involvement of auxin distribution in root nodule development of Lotus japonicus

Kojiro Takanashi, Akifumi Sugiyama, Kazufumi Yazaki

K Takanashi $\cdot$ A Sugiyama $\cdot$ K Yazaki

Research Institute for Sustainable Humanosphere,

Kyoto University, Gokasho, Uji 611-0011, Japan

* Corresponding author

K Yazaki

e-mail: yazaki@rish.kyoto-u.ac.jp

Tel. +81-774-38-3617

Fax. $+81-774-38-3623$ 


\begin{abstract}
The symbiosis between legume plants and rhizobia causes the development of new organs, nodules, which function as an apparatus for nitrogen fixation. In this study, the roles of auxin in nodule development in Lotus japonicus have been demonstrated using molecular genetic tools and auxin inhibitors. The expression of an auxin-reporter GH3 fused to $\beta$-glucuronidase (GUS) was analyzed in L. japonicus roots, and showed a strong signal in the central cylinder of the root, whereas upon rhizobium infection, generation of GUS signal was observed at the dividing outer cortical cells during the first nodule cell divisions. When nodules were developed to maturity, strong GUS staining was detected in vascular tissues of nodules, suggesting distinct auxin involvement in the determinate nodule development. Numbers and the development of nodules were affected by auxin transport inhibitors (1-naphtylphthalamic acid; NPA and tri-indobenzoic acid; TIBA), and by a newly synthesized auxin antagonist, $\alpha^{-}$(phenyl ethyl-2-one)-indole-3-acetic acid (PEO-IAA). The common phenotypical alteration by these auxin inhibitors was the inhibition in forming lenticel, which is normally developed on the nodule surface from the root outer cortex. The inhibition of lenticel formation was correlated with the inhibition of nodule vascular bundle development. These results indicate that auxin is required for the normal development of determinate nodules in a multidirectional manner.
\end{abstract}

Keywords Auxin $\cdot$ Lenticel $\cdot$ Lotus japonicus $\cdot$ Nodule formation $\cdot$ PEO-IAA

$\begin{array}{ll}\text { Abbreviations } & \\ \text { DsRed } & \text { Discoma sp. red fluorescent protein } \\ \text { dpi } & \text { days post inoculation } \\ \text { GUS } & \beta \text { - glucuronidase } \\ \text { NPA } & 1 \text {-naphtylphthalamic acid } \\ \text { PEO-IAA } & \alpha \text {-(phenyl ethyl-2-one)- indole-3-acetic acid } \\ \text { TIBA } & \text { tri-indobenzoic acid }\end{array}$




\section{Introduction}

Legume plants can establish symbiosis with rhizobia by forming a nitrogen-fixing apparatus called nodules, which are mostly developed on roots following legume-rhizobium signal exchanges that trigger the plant meristem formation that allows bacterial invasion from plant root hairs to underlying cortical cells (Brewin 2004). The initiation of nodules by rhizobia is stimulated by lipochitin oligosaccharides, also called Nod factors (Denarie et al. 1996), and the start of cell division involves the re-initiation of the cell cycle in the cortical and pericycle cells of the host plant root. In indeterminate legume plants, nodules are initiated from the inner cortex and form a persistent nodule meristem, which allows continuous growth, and leads to the formation of elongated nodules, whereas in determinate legumes nodules are mostly developed from outer cortical cells and form spherical nodules (Hirsch 1992). This nodule formation process is regulated by several phytohormones, such as auxin, cytokinins, gibberellins, and brassinosteroids as positive regulators of nodule formation (Ferguson et al. 2005; Frugier et al. 2008; Maekawa et al. 2009; Mathesius 2008), while ethylene, jasmonic acid and abscic acid as negative regulators (Ding et al. 2008; Nakagawa and Kawaguchi 2006; Penmetsa et al. 2008).

Auxin regulates plant growth and development in a highly sophisticated manner, in particular auxin functions by the regulated polar movement along the vertical axis leading to its concentration gradient through-out the plant. Since the possible involvement of auxin in nodule formation was first reported by Thimann in 1936, auxin distribution during nodulation has been studied in particular with indeterminate nodules (Thimann 1936). GH3 and DR5 promoters are often used as auxin reporter genes. In white clover (Trifolium repens), Mathesius and coworkers reported that rhizobia caused a reduction in the GH3 signal at the site of infection and at the area beneath. In their study, GH3 was observed to be highly expressed in early dividing pericycle and cortical cells of nodules, and subsequently, the 
expression decreased in the forming primordium. Finally, GH3 expression remained only in the nodule meristem and the vascular bundles (Mathesius et al. 1998). A similar expression pattern was also observed in Medicago truncatura using a DR5 promoter (Huo et al. 2006). Compared to these indeterminate nodules, auxin distribution of determinate nodules was seldom studied. In the determinate nodulating legume Lotus japonicus, GH3 expression did not disappear below the site of infection, but was found in the first dividing outer cortical cells, suggesting that there is a different auxin contribution pattern between determinate and indeterminate nodules (Pacios-Bras et al. 2003).

Inhibitors of auxin transport, i.e., 1-naphtylphthalamic acid (NPA) and tri-indobenzoic acid (TIBA) have been generally used to observe developmental effects on changes in auxin transport. NPA is thought to interfere with the intracellular cycling of the PIN-FORMED (PIN) proteins between the plasma membrane and endosomal vesicles (Blakeslee et al. 2005; Geldner et al. 2001). NPA also inhibits the auxin transport mediation by ATP-binding cassette proteins by binding these membrane proteins (Bailly et al. 2008). Several classes of flavonoids show a similar effect on auxin transport as NPA in white clover and also in the non-leguminous plant Arabidopsis thaliana (Brown et al. 2001; Jacobs and Rubery 1988; Mathesius et al. 1998). As another biochemical tool to study auxin functions, tert -butoxycarbonylaminohexyl-indole-3-acetic acid (BH-IAA) was reported to be an auxin antagonist (Hayashi et al. 2008). This $\alpha$-alkyl-IAA specifically binds to the auxin binding site of TIR1/AFBs auxin receptors and blocks their functions in many plant species such as Arabidopsis, rice (Oryza sativa) and moss (Physcomitrella patens). More recently, a-(phenyl ethyl-2-one)-indole-3-acetic acid (PEO-IAA) has been provided by Dr. Hayashi as another a-alkyl-IAA that shows more potent anti-auxin activity, and reveals the antagonistic activities to auxin-responsive gene expression, cell division, and the elongation pathway mediated by SCF TIR1/AFBs (Hayashi et al. unpublished data). In this study, we have shown the auxin distribution in the determinate nodules of $L$. japonicus using auxin inhibitors of different mechanisms and have found that the development of lenticels and nodule vascular bundles 
was strongly affected by auxin during the nodulation process.

\section{Materials and methods}

Plant materials, rhizobia strain and growth conditions

Lotus japonicus B129 Gifu and its GH3:GUS transgenic line, Lj3632.5.127, (kindly provided by

Dr. Herman P. Spaink, Leiden State University, Netherlands) were used in this work

(Pacios-Bras et al. 2003). All analyses were conducted in a cultivation chamber under a 16 -h day/8-h night cycle at a temperatures of $23^{\circ} \mathrm{C}$. For inoculation, Mesorhizobium loti

MAFF303099 carrying the DsRed (Discoma sp. red fluorescent protein) reporter gene (kind gift from Dr. Makoto Hayashi, National Institute of Agrobiological Sciences, Japan) was cultured overnight in TY medium at $28^{\circ} \mathrm{C}$ (Beringer 1974).

Treatment with auxin inhibitors

To study the effect of auxin transport inhibitors and auxin antagonist on plant growth and nodulation, NPA (TCI, Tokyo, Japan), TIBA (Sigma-Aldrich, St. Louis, MO), or PEO-IAA (kindly provided from Dr. Ken-ichiro Hayashi, Okayama University of Science, Japan) were dissolved in dimethyl sulfoxide (DMSO) and used to treat L. japonicus. Seeds were surface-sterilized with a $1 \%$ sodium hypochloride solution for $10 \mathrm{~min}$, rinsed five times with sterile distilled water, then germinated on water agar plates $(0.8 \%)$.

For nodulation experiments, five-day-old seedlings were transferred to plant boxes filled with sterile fine vermiculite with $100 \mathrm{ml}$ of 1/2 B\&D liquid medium (Broughton and Dilworth 1971), to which $100 \mu$ of either TIBA, NPA, or PEO-IAA were added with final concentration of 10 or $100 \mu \mathrm{M}$, and $10^{8}$ cells of $M$. lot $i$ was inoculated after two days. Plants grown on 1/2 B\&D medium containing the same volume of DMSO was used as a control. After 
19 days plants were sampled and their nodules including primordia were observed under a digital stereomicroscope system (VB-S20, Keyence, Osaka, Japan). Nodule primodia were defined as nodules with a diameter of $0.55 \mathrm{~mm}$ or less. Total root growth was evaluated as the sum of main and lateral root lengths.

To evaluate the effect of PEO-IAA on normal growth, five-day-old seedlings were transferred on 1/2 B\&D plate containing PEO-IAA. After 7 days plants were sampled and their phenotypes were observed under a stereomicroscope VB-S20 (Keyence). For scanning electron microscopy, roots were put on a dental impression material (Provil novo Light, Heraeus Kulzer, Wehrheim, Germany). After 2 hrs the negative molds were peeled and then filled with epoxy resin (GM-6600, Blenny Giken, Isezaki, Japan). The replicas were polymerized at room temperature for $48 \mathrm{hrs}$. The positive resin replicas were peeled from the negative molds and examined with a scanning electron microscope (S3500N, Hitachi, Tokyo, Japan).

For chloral hydrate clearance, nodules were fixed in fixative solution (ethanol : acetic acid $=3: 1$ ) for $3 \mathrm{hrs}$, and then hydrated through an ethanol series. The fixed samples were immersed in clearing solution containing $4 \mathrm{mg} / \mathrm{ml}$ chloral hydrate (Wako, Osaka, Japan) and $0.5 \mathrm{ml} / \mathrm{ml}$ glycerol at $4^{\circ} \mathrm{C}$ for a week, and then observed under a microscope (Axioscope2, Zeiss, Oberkochen, Germany).

Histochemical analysis of GH3:GUS transformant of $L$. japonicus

For GUS staining, tissues were prefixed in ice-cold $90 \%$ acetone for $15 \mathrm{~min}$, rinsed once with cold water, immersed with staining solution (50 mM sodium phosphate buffer, $\mathrm{pH}$ 7.0, 0.1\% Triton X-100, $0.5 \mathrm{mM}$ potassium ferrocyanide, $0.5 \mathrm{mM}$ potassium ferricyanide, and $1 \mathrm{mM}$ $\mathrm{X}$-Gluc), and incubated at $37^{\circ} \mathrm{C}$ for $40 \mathrm{~min}$. The stained samples were dehydrated through an ethanol series. The fixed samples were embedded in Technovit 7100 (Heraeus Kulzer) according to the manufacturer's protocol. Tissue sections (10 $\mu \mathrm{m}$ thick) prepared with a microtome (RM2155, Leica, Wetzlar, Germany) were mounted on slides and observed with a 
microscope (Axioscope2).

\section{Results}

Distribution of auxin in nodule development

The auxin-regulated soybean promoter GH3 (Hagen et al. 1991) fused to a reporter gene has provided a molecular tool to monitor auxin distribution in, among others, leguminous plants. Using GH3:GUS transformants we have investigated the auxin localization in developing nodules of $L$. japonicus. In uninoculated $L$. japonicus root, strong GUS staining was observed in the central cylinder (Fig. 1a, b), which represents high auxin level in these root tissues. At two days post inoculation (dpi) of $M$. loti, the GUS activity became detectable in part of root cortex, where a young nodule primordium was developing (Fig. 1c). When a section was prepared from this region, the cell division was seen in cortical cells, where GUS staining was observed at the basal part connecting the vascular tissues of the main root (closed arrow in Fig. 1d), and at the front of the young developing nodule as well, which is still under root epidermis (open arrow at Fig. 1d). In mature nodules (14 dpi), strong GUS staining was observed surrounding the infected zone of the nodule (Fig. 1e). The cross-section of the mature nodule revealed the strong GUS staining at vascular tissues of the nodule, and the continuous signal was seen at the root vascular tissues, from which a nodule vascular bundle was developed (Fig. 1f). These data strongly suggest that the possible involvement of auxin in the development of determinate nodules, which is consistent with the observation by Pacios-Bras (Pacios-Bras et al. 2003).

Effects of inhibitors of auxin transport on nodule formation in L. japonicus

Auxin is mainly synthesized in the apical region including shoot apical meristem and young 
leaves, and transported in a basipetal direction in the stem, and in an acropetal direction in the root (Baluska et al. 2005). This polar transport of auxin maintains the gradient of auxin concentration in a plant body, which is essential for normal plant growth and development. To test the effect of this polar auxin transport on the nodulation process, plants were treated with auxin transport inhibitors, such as NPA and TIBA. Plants grown in the presence of NPA at concentration of $10 \mu \mathrm{M}$ and $100 \mu \mathrm{M}$ showed an apparent reduction in the total root length $(70 \%$ and $73 \%$ inhibition, respectively) and nodule numbers (Fig. 2a, b). When plants were treated with $10 \mu \mathrm{M}$ of TIBA, a weak inhibition in the root growth (19\%) was observed while the nodule number was strongly reduced. Interestingly, a clear increment in the number of nodule primordia was observed when plants were treated with $100 \mu \mathrm{M}$ of TIBA, while root length was strongly reduced (68\% inhibition) at this concentration. Because NPA and TIBA inhibited the root growth of L. japonicus in particular at $100 \mu \mathrm{M}$, the reduction in nodule number might be due to an indirect effect of auxin transport inhibition, at least in part.

Effects of auxin antagonist on nodule formation

A newly synthesized auxin antagonist, PEO-IAA, binds to TIR1/AFBs receptors and blocks their functions leading to an auxin defective phenotype. To evaluate the direct auxin effects on nodulation, we employed this compound in this study. To investigate the effective dose of PEO-IAA in L. japonicus, we first observed the growth phenotype in the presence of different concentrations of PEO-IAA. At $10 \mu \mathrm{M}$, L. japonicus root elongation was slightly enhanced, but this auxin antagonist started to inhibit from $100 \mu \mathrm{M}$ on agar plates, and at $300 \mu \mathrm{M}$ the main root growth was strongly inhibited (Fig. 3a, b). We also found that PEO-IAA inhibited root hair emergence and development at low concentrations as 10 to $30 \mu \mathrm{M}$ (supplementary Fig. S1a, b).

In L. japonicus, the rhizobium infection occurs via infection threads that pass through root hairs in the root cortex, and then the bacteria are distributed to the cells, which become infected symbiosome-containing nitrogen-fixing cells (Karas et al. 2005; van Spronsen et al. 
2001). It was also reported that rhizobia could infect a root hairless mutant through cortical root hairs, which were induced by Nod factors (Karas et al. 2005). In that case, reduction of nodule number and increase of nodule primordia were observed in the root hairless mutant at 21 dpi. To study the effect of PEO-IAA on nodulation we inoculated M. loti on L. japonicus grown in plant boxes filled with vermiculite, which had been treated with $10 \mu \mathrm{M}$ or $100 \mu \mathrm{M}$ PEO-IAA. The results are shown in Fig. 4a and 4b. Surprisingly, when plants were grown on vermiculites, there was no significant difference in the development of root hairs even at the high concentration of PEO-IAA, probably due to the apparent difference in the effective concentration of PEO-IAA between on agar plate, which gives more precise effective concentration by the tight contact of entire roots with agar medium, and in vermiculite, in which contact surface of root tissues with inhibitor-containing vermiculite particles is limited. The number, size and the typical red color of nodules of $L$. japonicus treated with $10 \mu \mathrm{M}$ or 100 $\mu \mathrm{M}$ PEO-IAA were not influenced either, but we found one clear phenotype alteration, i.e., the lenticels on the surface of nodules disappeared under the treatment of PEO-IAA (100 $\mu \mathrm{M})$ (Fig. 5a). The development of lenticels, which arise from specific phellogen cells, was also strongly inhibited by the auxin transport inhibitors (Fig. 5a). Lenticels develop above the nodule vascular bundles which were postulated to provide growth substances to the lenticels (Pankhurst and Sprent 1975). To investigate the effect of auxin inhibitors on the development of vascular bundles, nodules were cleared with chloral hydrate after treatment with auxin inhibitors. Developed vascular bundles were observed in nodules with lenticels (control), while in nodules treated with auxin inhibitors, neither vascular bundle nor lenticels were observed accordingly (Fig. 5b). These correlations were also observed in GH3:GUS nodules which were treated with auxin inhibitors (Fig. 5c). Fluorescence of DsRed carried by M. loti was detected in all nodules observed, indicating that no pseudonodule was developed by the treatment of these inhibitors (supplementary Fig. S2).

\section{Discussion}


Among several types of nodules in legume plants, indeterminate nodules and determinate nodules are well studied their nodulation process. In the former, for which alfalfa and $M$. truncatula are representatives, nodules are derived from the inner cortex of the root and develop a meristem, whereas in the latter (for instance, soybean and L. japonicus) nodules are derived from the outer cortex cells and grow via non-meristematic cell division. Due to these morphological and developmental differences, many comparisons have been made between these two types of nodules. Several previous reports suggested that auxin is involved in nodulation, especially in indeterminate nodules because, for example, nodules contain elevated levels of auxin, auxin response genes are differentially expressed during nodule initiation, auxin transport is inhibited by rhizobia, and auxin transport inhibitors can induce pseudonodules (Mathesius 2008). Compared to indeterminate nodules, the involvement of auxin on the development of determinate nodules is still largely unknown. In the present study, we have shown the distribution of auxin during the formation of determinate nodules, the effects of inhibitors of auxin polar transport and a new auxin antagonist on nodulation.

The GH3:GUS transformant of $L$. japonicus showed auxin responses during nodule development. In uninoculated root, GH3 expression was observed only in central cylinder (Fig. 1a, b), whereas in inoculated roots, GH3 expression started to increase in the outer cortical cells where cell divisions occurred in nodule primordia. It is also to be noted that the GH3 expression was connected to the main root vascular tissues. In mature nodules, GUS staining disappeared in both infected and non-infected cells derived from the cortex, whereas strong expression was observed in vascular tissues. These results suggest that auxin plays an important role in nodule formation, especially in the development of vascular tissues. Similar GUS expression was observed in dividing root cortex when $M$. loti was inoculated into $L$. japonicus, which was transformed with the GUS gene under the control of the Arabidopsis cytokinin-responsive gene, ARR5 (Lohar et al. 2004). Cytokinin signaling is necessary to induce cortical cell divisions and nodule organogenesis, because the gain-of-function mutant in 
the cytokinin receptor, LHK1, spontaneously develops nodules in the absence of rhizobia whereas loss-of-function mutant in LHK1 abolishes nodule primordium formation (Murray et al. 2007; Tirichine et al. 2007). Together with cytokinin, auxin may participate in the initiation of cell divisions in a coordinated fashion.

Polar auxin transport is mediated by cell-to-cell movement that is generated by a chemiosmotic model where the existence of auxin-carrier proteins localized to the plasma membrane responsible for the auxin uptake and efflux out of the cells has been proposed (Raven 1975; Rubery and Ar 1974). The model is rationalized by the asymmetric localization of the efflux carriers at one side of the cells, which determines the direction of the intercellular auxin movement in plants. In the current model, polar auxin transport is mediated by several different classes of transporter proteins i.e., AUXIN/LIKE-AUXIN (AUX/LAX) permeases (Kramer and Bennett 2006), PIN proteins (Teale et al. 2006; Vieten et al. 2007), and ABC proteins of the ABCB subfamily (Geisler and Murphy 2006). In L. japonicus, rhizobium inoculation induced GH3 expression and auxin transport was up-regulated after the treatment of purified Nod factors at a root tip (Pacios-Bras et al. 2003), which suggested that an increased auxin level is necessary for the nodulation process. We have demonstrated in this study the effects of auxin transport inhibitors on nodulation, i.e., the treatment of $L$. japonicus with NPA or TIBA altered the nodule number at concentrations $10 \mu \mathrm{M}$ and $100 \mu \mathrm{M}$, in which the plant growth was not drastically suppressed.

PEO-IAA can block auxin functions since this a-alkyl-IAA competitively binds to the auxin-binding site of receptor molecules TIR1/AFBs. Some auxin-deficient phenotypes of this compound are similar to those resulting from treatment with NPA, but most effects are different and more direct effects can be observed with the auxin antagonist (Hayashi et al. 2008). Thus, we investigated the effects of PEO-IAA on nodulation in L. japonicus. Although PEO-IAA affected the root growth and root hair formation in L. japonicus at 10 to $300 \mu \mathrm{M}$ in agar plates, the number of nodules was not strongly altered as compared to that of control at concentrations $10 \mu \mathrm{M}$ and $100 \mu \mathrm{M}$ in vermiculite. One striking effect of PEO-IAA was that this 
auxin antagonist strongly suppressed the development of lenticels on nodules in a similar manner as those with NPA and TIBA (Fig. 5a). We also found the inhibition of nodule vascular bundle development under the treatment of these inhibitors (Fig. 5b, c). The effective concentration of PEO-IAA for various auxin responses differs depending on the tissues, e.g., the inhibition of lenticel formation was observed at $100 \mu \mathrm{M}$ whereas root hair development was more sensitive (30 $\mu \mathrm{M})$ (Supplementary Fig. S1). Inhibition of lateral root formation was only observed at high concentrations of PEO-IAA such as $300 \mu \mathrm{M}$ in L. japonicus (Fig. 3c).

Lenticels develop opposite the nodule vascular bundle and are suggested to arise from specific phellogen cells in the nodule cortex. These cells become meristematic and by repeated divisions rupture the epidermis, whereby the lenticels appear on the nodule surface as bands of loosely packed tissue (Pankhurst and Sprent 1975). Lenticels regulate gas permeability of nodules and develop more extensively under low oxygen or waterlogged conditions, whereas during water insufficient condition or high oxygen pressure they collapse, or develop very little externally (Pankhurst and Sprent 1975; Walsh 1995). Grønlund et al. showed that the lenticel development was also inhibited as well as the vascular tissues, when the expression of two homeodomain proteins, Ljndx1 and Ljndx2, was suppressed (Grønlund et al. 2003). The relation between the lenticels and the nodule vascular system is unknown. However, due to their relative location, it was suggested that lenticel development is associated with growth substances supplied from the vascular system (Pankhurst and Sprent 1975). Taken together, our data suggested that auxin is also one of the candidates of the growth substances controlling lenticel formation, or that auxin is necessary to form the nodule vascular bundle and lack of lenticel may be an indirect effect of abnormal development of vascular bundle after treatment of these auxin inhibitors.

In this study, we have shown the involvement of auxin in the formation of vascular bundle and lenticel on the nodules. For further understanding of the auxin distribution and the role of auxin in the nodules of $L$. japonicus, identification and characterization of auxin transporter genes that respond to nodulation will be necessary. (Brown et al. 2001) 


\section{Acknowledgements}

We would like to thank National Bioresource Project (Lotus japonicus, Glycine max) for seeds of L. japonicus and Dr. Ken-ichiro Hayashi (Okayama University of Science, Japan) for the PEO-IAA. We also wish to thank Dr. Niels Sandal and Dr. Jens Stougaard (University of Aarhus, Denmark) and Dr. Herman P. Spaink (Leiden State University, Netherlands) for seeds of GH3:GUS transformed L. japonicus (Lj3632.5.127). We thank Dr. Takashi Aoyama (Kyoto University, Japan) for the technical assistance in scanning electron microscope and the sample preparation and Dr. Makoto Hayashi (National Institute of Agrobiological Sciences, Japan) for the $M$. loti carrying DsRed. This work was supported in part by Grant-in-Aid for Scientific Research (No. 21027022 to K.Y.) and by Research Fellowship from the Japan Society for the Promotion of Science for Young Scientists (No. 09J00170 to K.T.).

\section{References}

Bailly A, Sovero V, Vincenzetti V, Santelia D, Bartnik D, Koenig BW, Mancuso S, Martinoia E, Geisler M (2008) Modulation of p-glycoproteins by auxin transport inhibitors is mediated by interaction with immunophilins. J Biol Chem 283: 21817-21826

Baluska F, Barlow PW, Baskin TI, Chen RJ, Feldman L, Forde BG, Geisler M, Jernstedt J, Menzel D, Muday GK, Murphy A, Samaj J, Volkmann D (2005) What is apical and what is basal in plant root development? Trends Plant Sci 10: 409-411

Beringer JE (1974) R factor transfer in Rhizobium-leguminosarum. J Gen Microbiol 84: 188-198

Blakeslee JJ, Peer WA, Murphy AS (2005) Auxin transport. Curr Opin Plant Biol 8: 494-500 Brewin NJ (2004) Plant cell wall remodelling in the rhizobium-legume symbiosis. Crit Rev Plant Sci 23: 293-316

Broughton WJ, Dilworth MJ (1971) Control of leghaemoglobin synthesis in snake beans. 
Biochem J 125: 1075-1080

Brown DE, Rashotte AM, Murphy AS, Normanly J, Tague BW, Peer WA, Taiz L, Muday GK (2001) Flavonoids act as negative regulators of auxin transport in vivo in Arabidopsis. Plant Physiol 126: 524-535

Denarie J, Debelle F, Prome JC (1996) Rhizobium lipo-chitooligosaccharide nodulation factors: Signaling molecules mediating recognition and morphogenesis. Annu Rev Biochem 65: $503-535$

Ding YL, Kalo P, Yendrek C, Sun JH, Liang Y, Marsh JF, Harris JM, Oldroyd GED (2008) Abscisic acid coordinates Nod factor and cytokinin signaling during the regulation of nodulation in Medicago truncatula. Plant Cell 20: 2681-2695

Ferguson BJ, Ross JJ, Reid JB (2005) Nodulation phenotypes of gibberellin and brassinosteroid mutants of pea. Plant Physiol 138: 2396-2405

Frugier F, Kosuta S, Murray JD, Crespi M, Szczyglowski K (2008) Cytokinin: secret agent of symbiosis. Trends Plant Sci 13: 115-120

Geisler M, Murphy AS (2006) The ABC of auxin transport: The role of p-glycoproteins in plant development. FEBS Lett 580: 1094-1102

Geldner N, Friml J, Stierhof YD, Jurgens G, Palme K (2001) Auxin transport inhibitors block PIN1 cycling and vesicle traficking. Nature 413: 425-428

Grønlund M, Gustafsen C, Roussis A, Jensen D, Nielsen LP, Marcker KA, Jensen EO (2003) The Lotus japonicus ndx gene family is involved in nodule function and maintenance. Plant Mol Biol 52: 303-316

Hagen G, Martin G, Li Y, Guilfoyle TJ (1991) Auxin-induced expression of the soybean GH3 promoter in transgenic tobacco plants. Plant Mol Biol 17: 567-579

Hayashi K, Tan X, Zheng N, Hatate T, Kimura Y, Kepinski S, Nozaki H (2008) Small-molecule agonists and antagonists of F-box protein-substrate interactions in auxin perception and signaling. Proc Natl Acad Sci USA 105: 5632-5637

Hirsch AM (1992) Developmental biology of legume nodulation. New Phytol 122: 211-237 
Huo XY, Schnabel E, Hughes K, Frugoli J (2006) RNAi phenotypes and the localization of a protein :: GUS fusion imply a role for Medicago truncatula PIN genes in nodulation. J Plant Growth Regul 25: 156-165

Jacobs M, Rubery PH (1988) Naturally-occurring auxin transport regulators. Science 241: 346-349

Karas B, Murray J, Gorzelak M, Smith A, Sato S, Tabata S, Szczyglowski K (2005) Invasion of Lotus japonicus root hairless 1 by Mesorhizobium loti involves the nodulation factor-dependent induction of root hairs. Plant Physiol 137: 1331-1344

Kramer EM, Bennett MJ (2006) Auxin transport: a field in flux. Trends Plant Sci 11: 382-386

Lohar DP, Schaff JE, Laskey JG, Kieber JJ, Bilyeu KD, Bird DM (2004) Cytokinins play opposite roles in lateral root formation, and nematode and Rhizobial symbioses. Plant $\mathrm{J}$ 38: $203-214$

Maekawa T, Maekawa-Yoshikawa M, Takeda N, Imaizumi-Anraku H, Murooka Y, Hayashi M (2009) Gibberellin controls the nodulation signaling pathway in Lotus japonicus. Plant $\mathrm{J}$ 58: $183-194$

Mathesius U (2008) Auxin: at the root of nodule development? Funct Plant Biol 35: 651-668

Mathesius U, Schlaman HRM, Spaink HP, Sautter C, Rolfe BG, Djordjevic MA (1998) Auxin transport inhibition precedes root nodule formation in white clover roots and is regulated by flavonoids and derivatives of chitin oligosaccharides. Plant J 14: 23-34

Murray JD, Karas BJ, Sato S, Tabata S, Amyot L, Szczyglowski K (2007) A cytokinin perception mutant colonized by Rhizobium in the absence of nodule organogenesis. Science 315: 101-104

Nakagawa T, Kawaguchi M (2006) Shoot-applied MeJA suppresses root nodulation in Lotus japonicus. Plant Cell Physiol 47: 176-180

Pacios-Bras C, Schlaman HRM, Boot K, Admiraal P, Langerak JM, Stougaard J, Spaink HP (2003) Auxin distribution in Lotus japonicus during root nodule development. Plant Mol Biol 52: 1169-1180 
Pankhurst CE, Sprent JI (1975) Surface features of soybean root nodules. Protoplasma 85: $85-98$

Penmetsa RV, Uribe P, Anderson J, Lichtenzveig J, Gish JC, Nam YW, Engstrom E, Xu K, Sckisel G, Pereira M, Baek JM, Lopez-Meyer M, Long SR, Harrison MJ, Singh KB, Kiss GB, Cook DR (2008) The Medicago truncatula ortholog of Arabidopsis EIN2, sickle, is a negative regulator of symbiotic and pathogenic microbial associations. Plant J 55: 580-595

Raven JA (1975) Transport of indoleacetic-acid in plant-cells in relation to $\mathrm{pH}$ and electrical potential gradients, and Its significance for polar IAA transport. New Phytol 74: 163-172

Rubery PH, Ar S (1974) Carrier-mediated auxin transport. Planta 118: 101-121

Teale WD, Paponov IA, Palme K (2006) Auxin in action: signalling, transport and the control of plant growth and development. Nature Rev Mol Cell Biol 7: 847-859

Thimann KV (1936) On the physiology of the formation of nodules on legume roots. Proc Natl Acad Sci USA 22: 511-514

Tirichine L, Sandal N, Madsen LH, Radutoiu S, Albrektsen AS, Sato S, Asamizu E, Tabata S, Stougaard J (2007) A gain-of-function mutation in a cytokinin receptor triggers spontaneous root nodule organogenesis. Science 315: 104-107

van Spronsen PC, Grønlund M, Bras CP, Spaink HP, Kijne JW (2001) Cell biological changes of outer cortical root cells in early determinate nodulation. Mol Plant Microbe In 14: 839-847

Vieten A, Sauer M, Brewer PB, Friml J (2007) Molecular and cellular aspects of auxin-transport-mediated development. Trends Plant Sci 12: 160-168

Walsh KB (1995) Physiology of the legume nodule and its response to stress. Soil Biol Biochem 27: 637-655 


\section{Figure Legends}

Fig. 1 GH3:GUS expression during the nodulation in L. japonicus. a GH3:GUS expression was observed in central cylinder of uninoculated root. b Cross section of a. c Enhanced GH3:GUS expression was observed in outer cortex of the root, where $M$. loti was inoculated. d Cross section of c. GH3:GUS expressed in vascular tissues of the main root, and basal (closed arrow) and apical parts (open arrow) of the nodule primordia. e In mature nodule, strong GH3:GUS expression was detected only in vascular tissues. f Cross section of e. Scale bars $100 \mu \mathrm{m}$

Fig. 2 Effect of auxin transport inhibitor on the nodule development. a Growth phenotype and b nodule number of $L$. japonicus treated with NPA and TIBA. The data are represented as averages of 18 individual plants, and values represent mean \pm SD. ${ }^{*} P<0.05$ and ${ }^{* *} P<0.01$ compared with control (DMSO) by ANOVA (Bonferroni test). Scale bars $1.0 \mathrm{~cm}$

Fig. 3 Effect of PEO-IAA on the growth of L. japonicus. Five-day-old seedlings were treated with PEO-IAA. After 7 days plants were sampled and the phenotype was observed. a Seedlings grown in the presence of PEO-IAA. Scale bars $1.0 \mathrm{~cm}$. b Main root length was measured after treatment of PEO-IAA. The data are represented as averages of 6 individual plants, and values represent mean $\pm \mathrm{SD} .{ }^{*} P<0.05$ compared with control by ANOVA (Bonferroni test).

Fig. 4 Effect of PEO-IAA on the nodule development. a Growth phenotype and $\mathbf{b}$ nodule numbers of L. japonicus. The growth was inhibited by PEO-IAA, but nodule number and development were not significantly affected. The data are represented as averages of 18 individual plants and values represent mean \pm SD. Scale bars $1.0 \mathrm{~cm}$

Fig. 5 Nodules of L. japonicus grown with PEO-IAA or auxin transport inhibitors. Five-day-old seedlings were treated with PEO-IAA, NPA or TIBA, respectively, and then inoculated with $M$. loti 2 days later. After 19 days plants were sampled and the phenotype of nodules was observed. 
a Developments of lenticels (yellow arrowheads) were inhibited by auxin inhibitors except plant treated with $10 \mu \mathrm{M}$ PEO-IAA. Scale bars $1.0 \mathrm{~mm}$. b Chloral-hydrate-cleared nodules showed the lack of nodule vascular bundles. Developments of nodule vascular bundles (white arrowheads) were also inhibited by auxin inhibitors in accordance with the inhibition of lenticels formation. Scale bars $200 \mu \mathrm{m}$. c Nodules of GH3:GUS transformant showed also the correlation of lack of lenticels and nodule vascular bundles. Scale bars $1.0 \mathrm{~mm}$. 


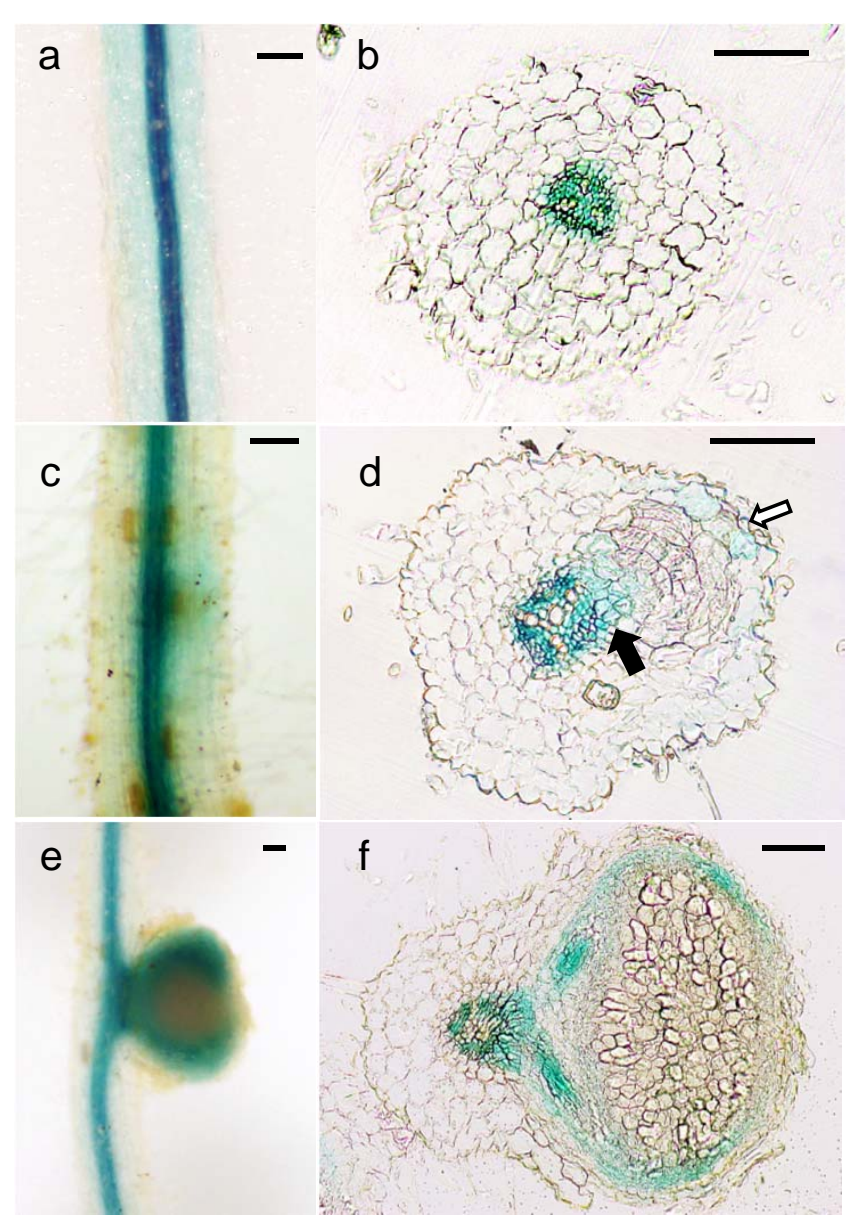

Fig. 1. Takanashi, et al. 
a

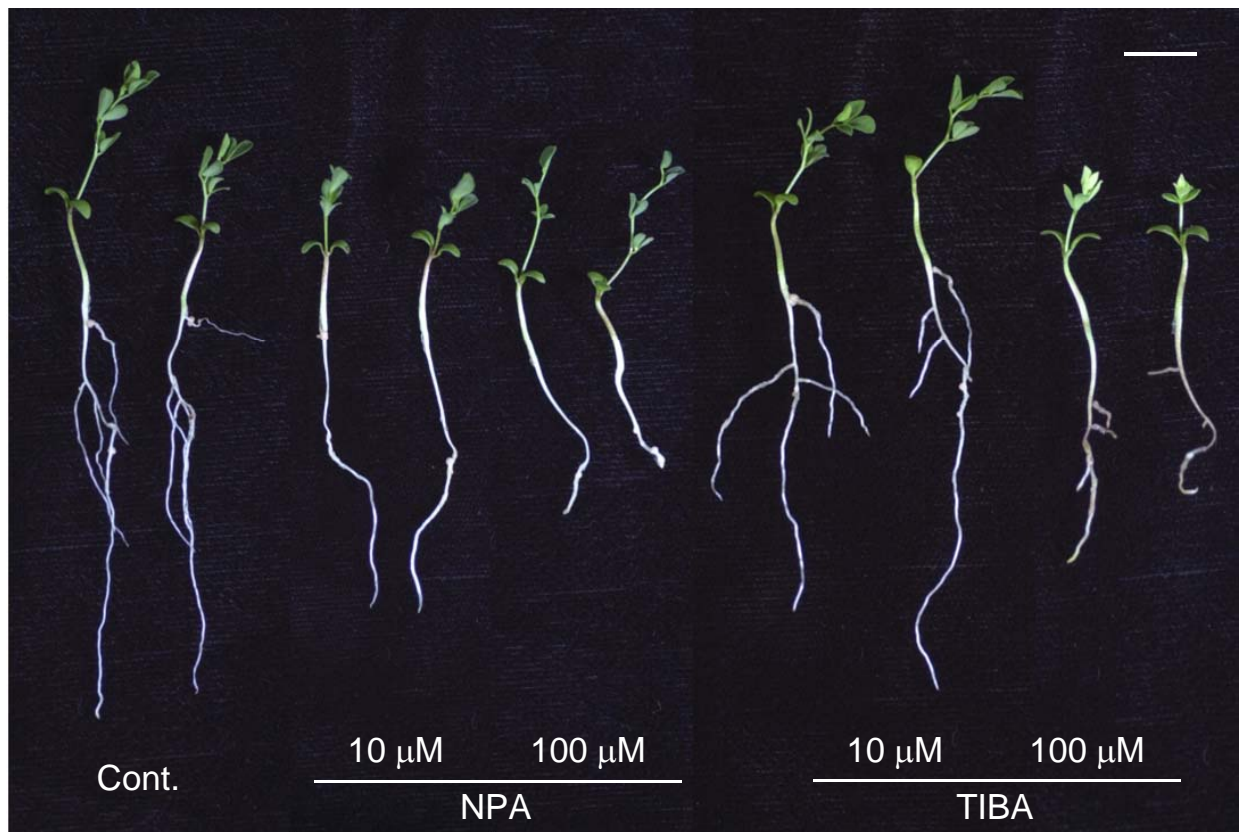

b

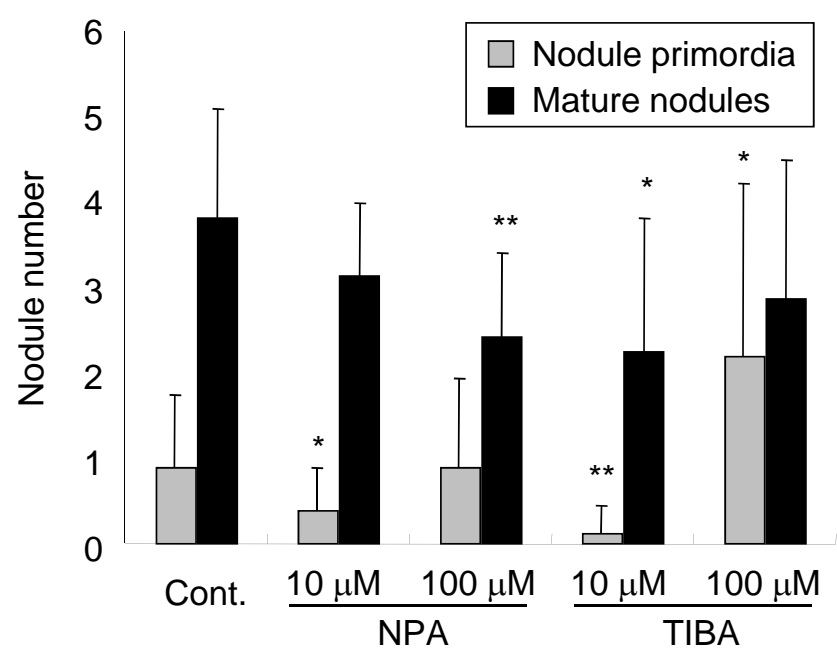

Fig. 2. Takanashi, et al. 

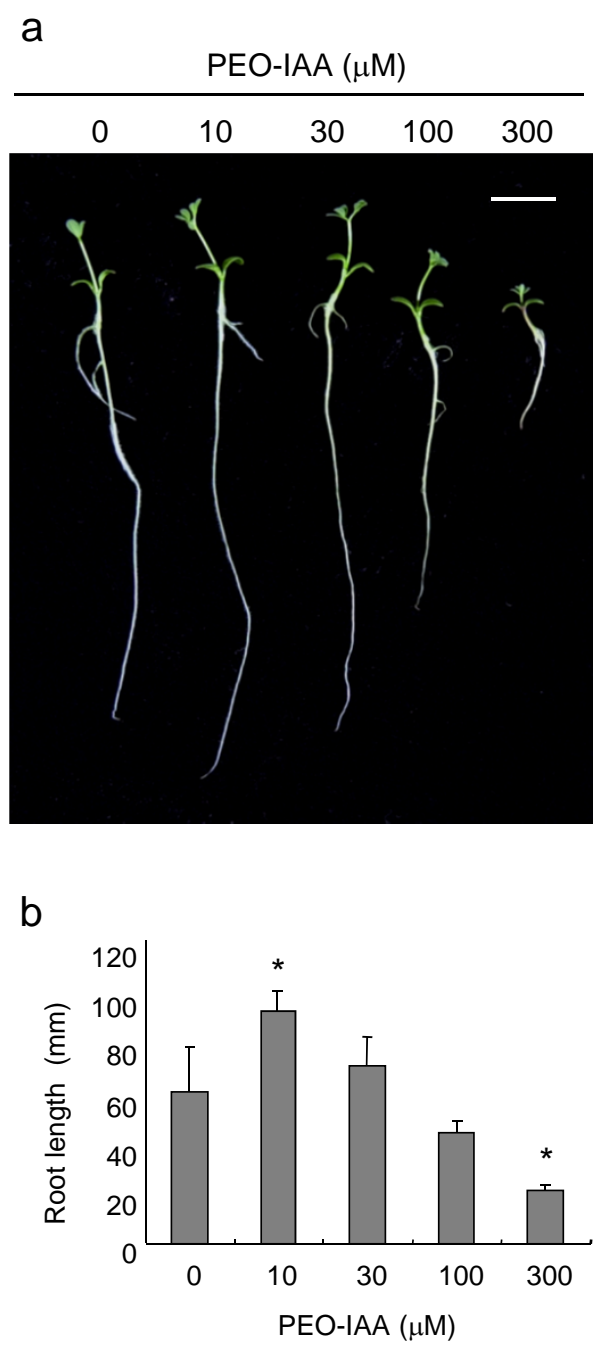

Fig. 3. Takanashi, et al. 
a
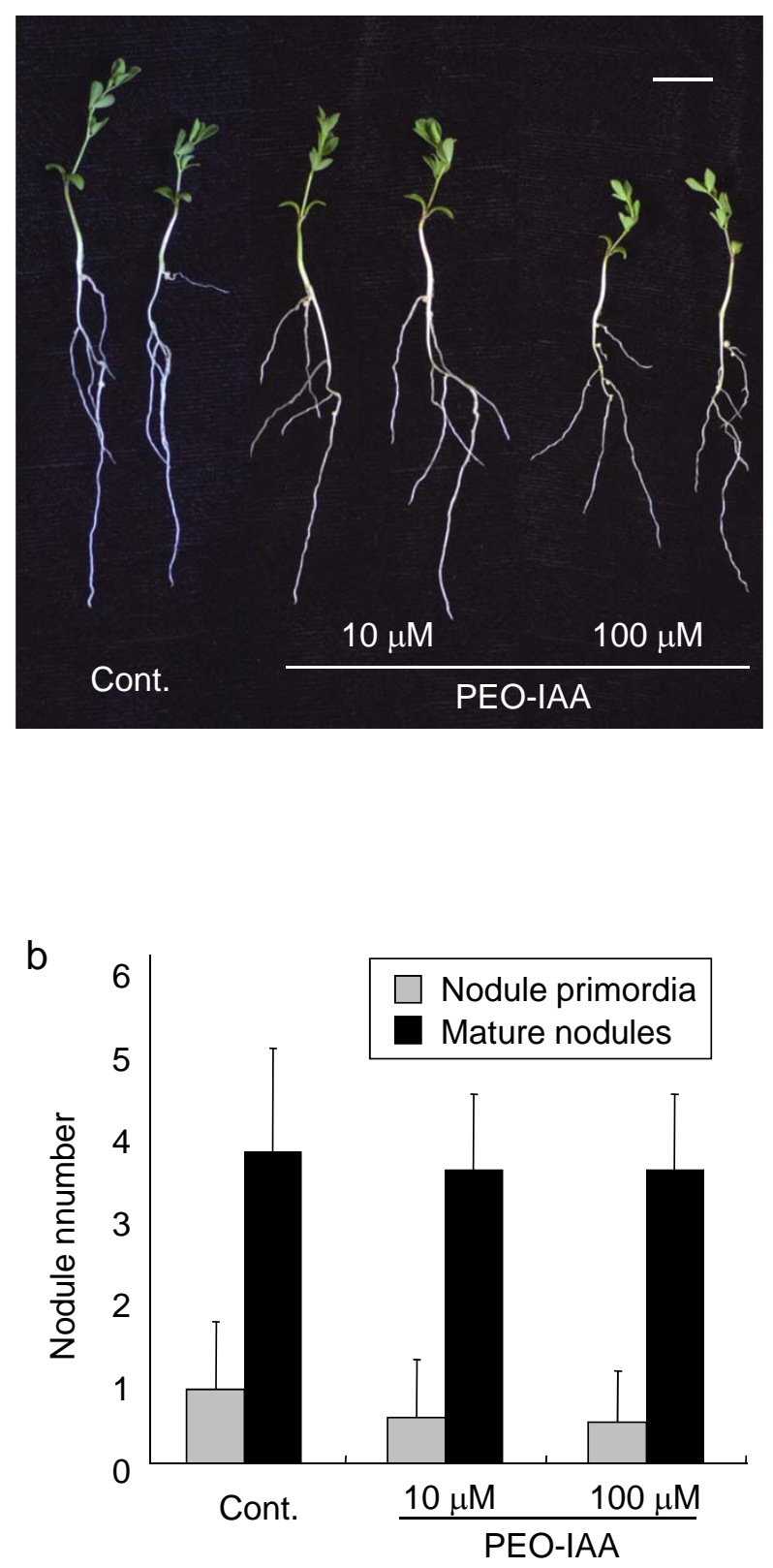

Fig. 4. Takanashi, et al. 
a

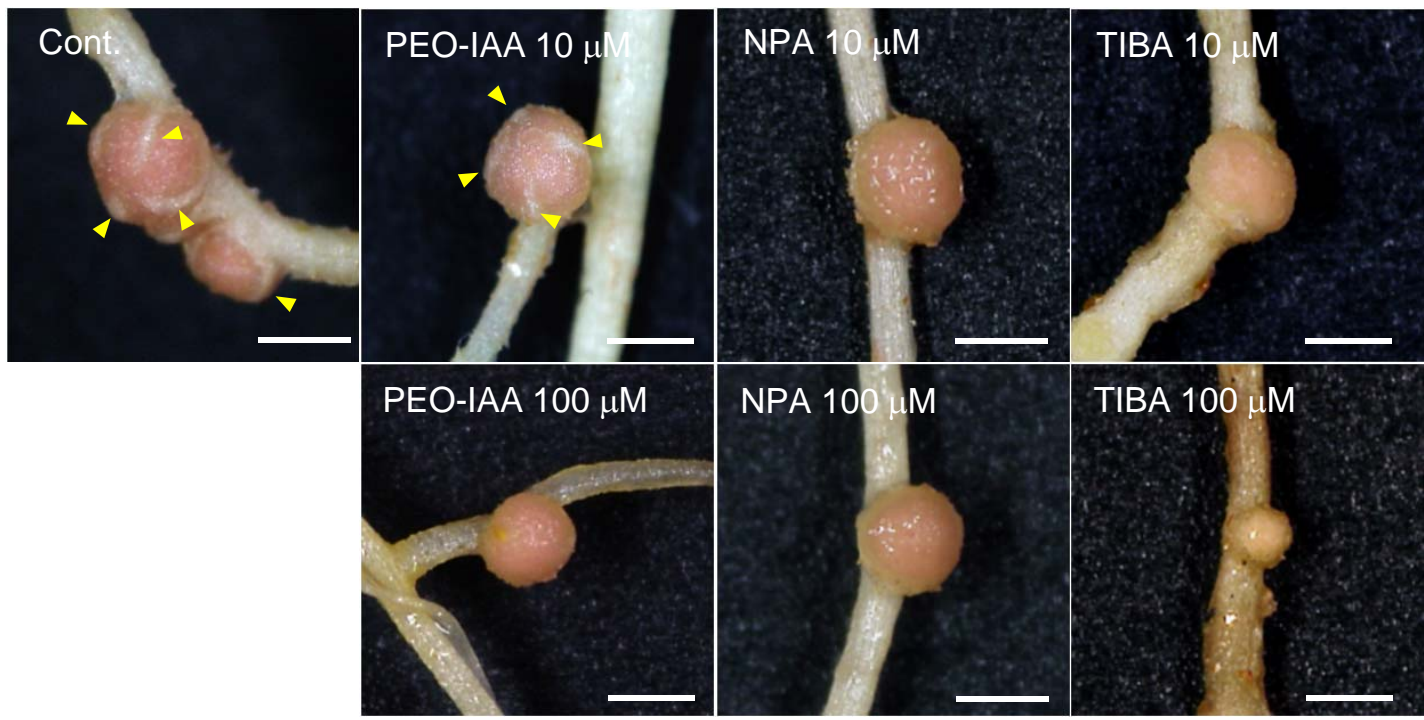

b
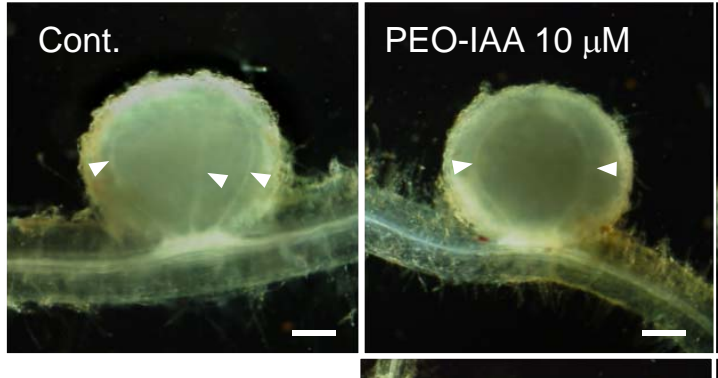

NPA $10 \mu \mathrm{M}$
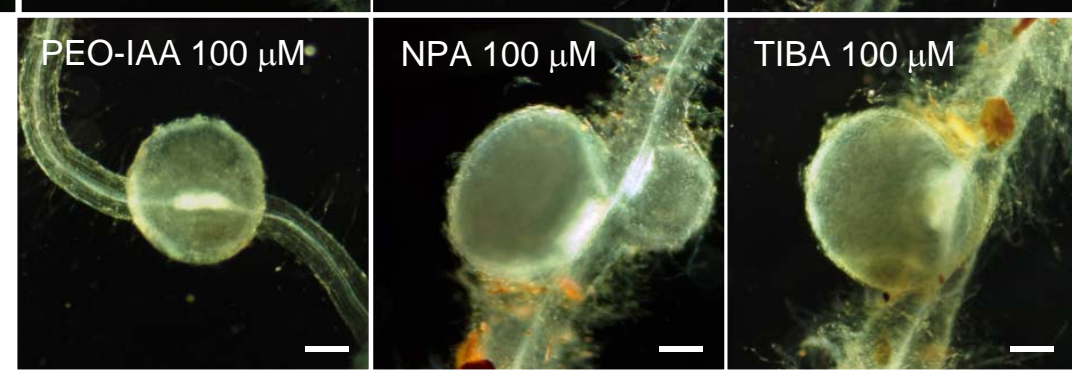

C

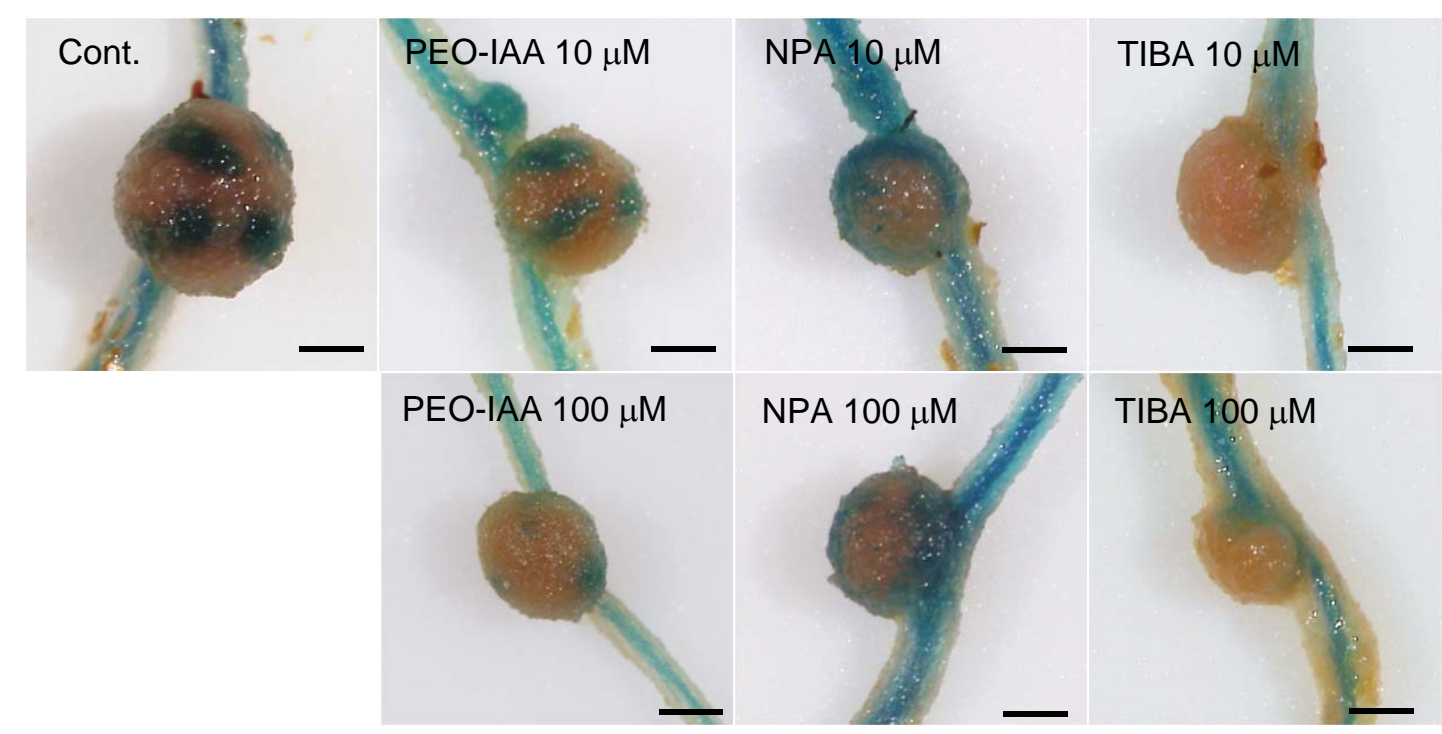

Fig. 5. Takanashi, et al. 
a

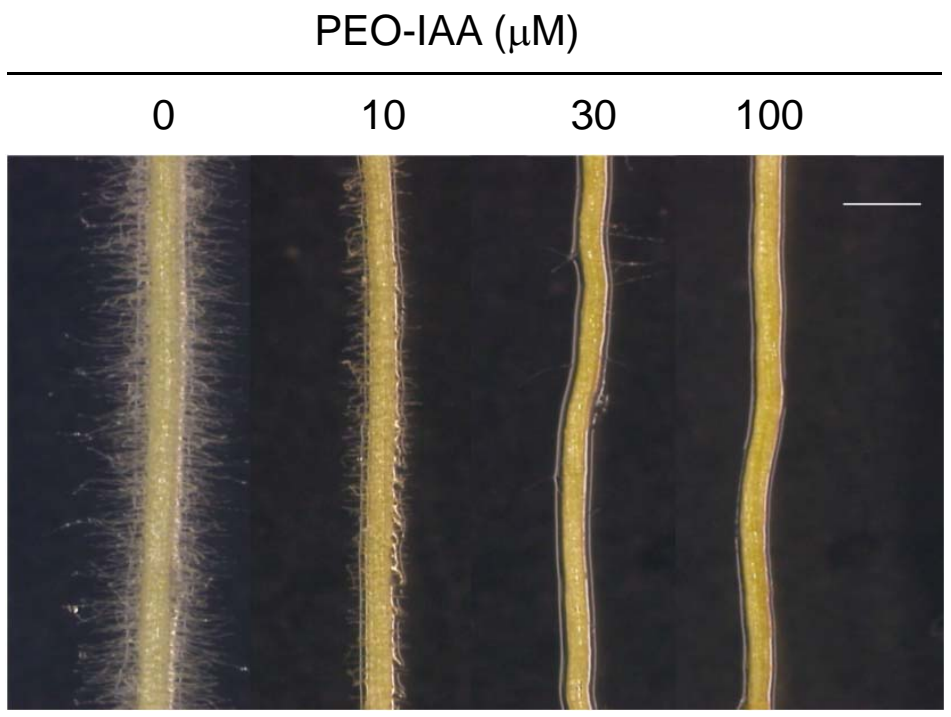

b

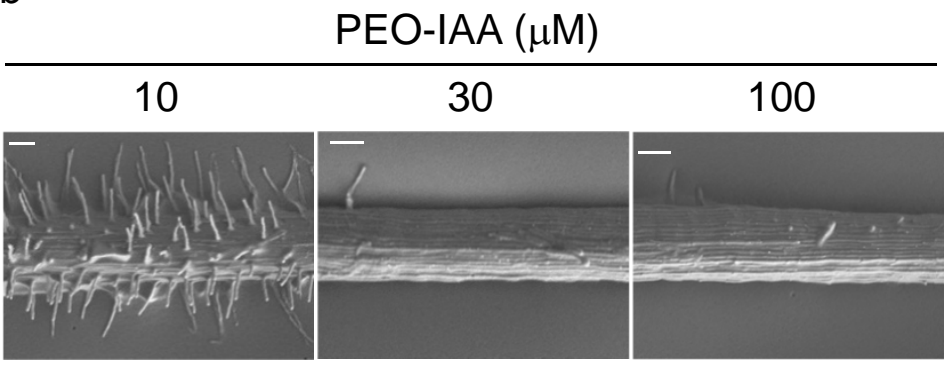

Supplementary Fig. S1 Effect of PEO-IAA on the root hair of $L$. japonicus. Fiveday-old seedlings were treated with PEO-IAA. After 7 days plants were sampled and the phenotype was observed. a Zone of mature root hairs. Development of root hair was inhibited under treatment of PEO-IAA. Scale bars $1.0 \mathrm{~mm}$. b Zone of root hair emergence. Scale bars $200 \mu \mathrm{m}$. 


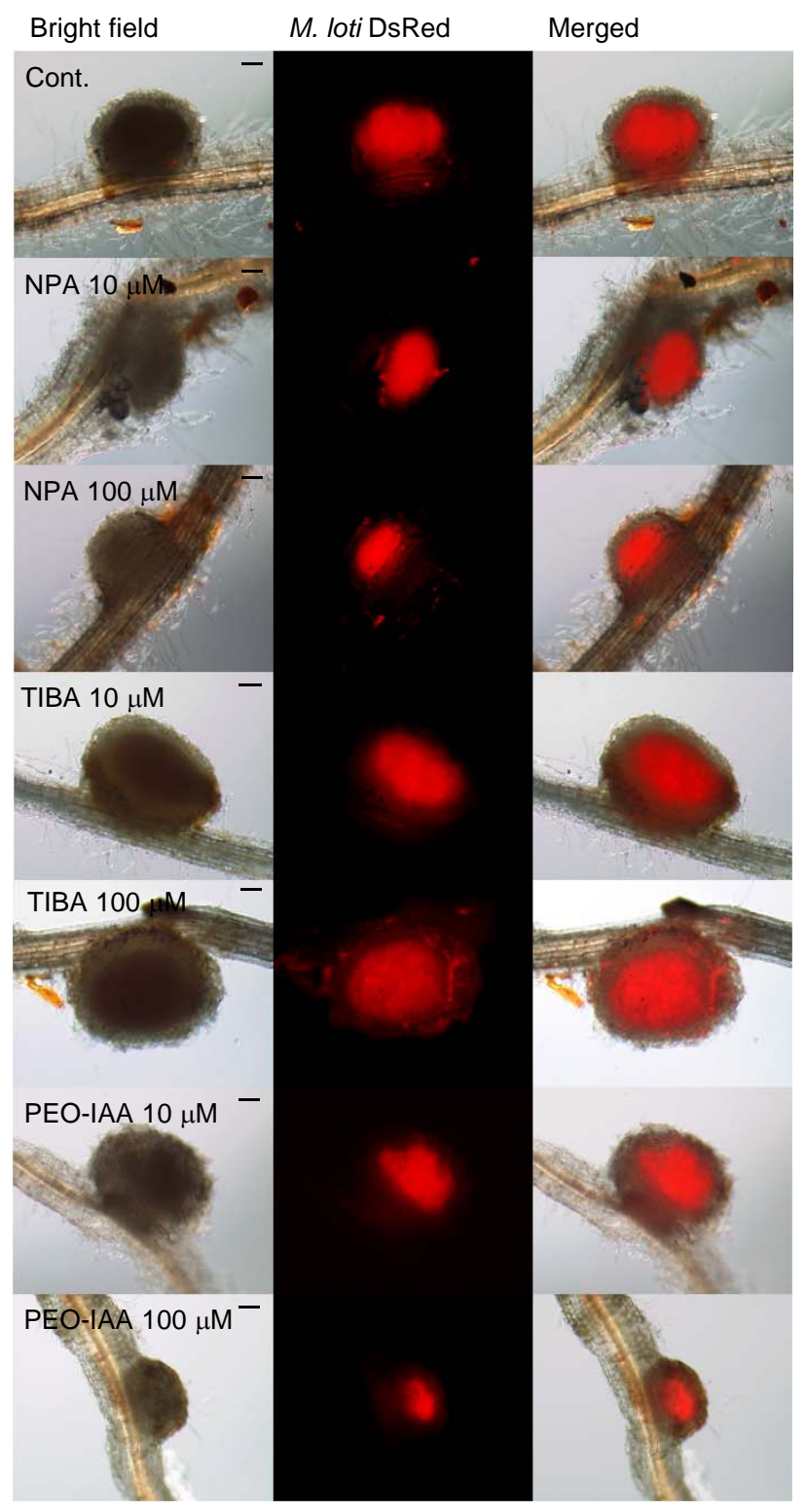

Supplementary Fig. S2 Effect of auxin inhibitors on the pseudonodule formation. Plants were inoculated with $M$. loti carrying DsRed reporter gene after application of auxin inhibitors. Fluorescents of DsRed were observed in all nodules. Scale bars $100 \mu \mathrm{m}$. 